\title{
Application of Wedges for the Reduction of the Space and Time-Dependent Harmonic Content in Squirrel-Cage Induction Motors
}

\author{
Konstantinos N. Gyftakis, Panagiotis A. Panagiotou, and Joya C. Kappatou \\ The Laboratory of Electromechanical Energy Conversion, Electrical and Computer Engineering Department, \\ University of Patras, Patras 26504, Greece \\ Correspondence should be addressed to Konstantinos N. Gyftakis; kosgyftak@upatras.gr \\ Received 30 April 2013; Revised 7 November 2013; Accepted 12 November 2013 \\ Academic Editor: George Labeas \\ Copyright (C) 2013 Konstantinos N. Gyftakis et al. This is an open access article distributed under the Creative Commons \\ Attribution License, which permits unrestricted use, distribution, and reproduction in any medium, provided the original work is \\ properly cited.

\begin{abstract}
The influence of the semimagnetic stator wedges of different sizes on the electromagnetic characteristics and the behavior of the induction motor is investigated. The study will be carried out with both analytical calculations and FEM analysis. The analytical calculations will take into account the stator and rotor slots, as well as the iron core saturation in order to study the spatial and time-dependent harmonic content of the air-gap magnetic flux density and electromagnetic torque. The size of the wedge plays an important role as it determines the tooth tips saturation, the high harmonic content of the air-gap magnetic flux density, and the electromagnetic characteristics of the induction motor.
\end{abstract}

\section{Introduction}

It is well known that the existence of space and time harmonics in the electromagnetic variables of a symmetrical induction motor, fed by symmetrical three-phase voltage system, depends on several causes. Mainly, it depends on the presence of stator and rotor slots and the magnetic saturation of the stator and rotor core, especially at the tooth tips [1]. As a consequence, torque oscillations, high frequency losses, vibrations, and noise are generated. Those undesired phenomena lead to less efficiency, temperature increase, reduction of the induction motor life cycle, and higher maintenance cost.

Since the induction motor is the most widely used electrical machine in industrial applications, there is a continuous research concerning the optimization of the motor's electromagnetic variables and behavior, as well as improved design aiming at the motor's longer life cycle [2-5].

Many methods have been proposed during the years, aiming at the reduction of higher rank harmonics. Such methods are the skewing, the construction of cage rotors with totally closed slots [6], and the construction of asymmetrical rotor slots [7]. Each one of these methods though, presents several disadvantages. Generally, the above methods have a negative impact on the power factor, due to the increased leakage flux. Furthermore, they result to reduced output power at nominal speed.

Another method proposed for the reduction of the airgap magnetic flux density harmonic content is the use of semimagnetic wedges for the closure of the stator slot openings. The wedges lead the flux in the slot opening and produce a more uniform flux density distribution in the air-gap but increase also the slot leakage flux. In [8-13], the authors have presented the influence of the stator slot openings on the induction motor's efficiency, which is greatly improved by applying stator wedges. Also, in [14-20] the positive effects of the use of magnetic wedges in the stator slot openings on the vibrations and noise of the induction motor have been presented. Moreover, in [21] one could see that the use of wedges had a negative impact on the starting behavior 
of the motor. In [22] the authors came to the result that the application of soft ferrite magnetic wedges was incapable of reducing the 5th asynchronous and synchronous torque. In addition, in [23] the authors show that the amplitude of the flux density and force waves originating from saturation increase when stator wedges are applied. Furthermore, in $[24,25]$ the detection of fallen out magnetic wedges was studied. A thermal evaluation of the wedges application was performed in [26]. Finally, in $[27,28]$ the dependence of the magnetic noise on the number and geometry of the motor's slots has been investigated.

In this work, the influence of semimagnetic wedges for the closure of the stator slot openings on the electromagnetic variables and the air-gap magnetic flux density harmonic content, in induction motors, will be thoroughly investigated, using both analytical calculations and FE analysis. Particularly, the influence of different sized semimagnetic wedges closing the stator slot openings on the electromagnetic characteristics, harmonic content, iron core saturation, and the behavior of the induction motor will be studied.

The investigation will be carried out in three steps. In the first part, through analytical formulas the space and time-dependent air-gap magnetic flux density content will be shown. The air-gap magnetic flux density and saturation related harmonics will be also presented. Finally, the harmonic index of the motor's electromagnetic torque will be demonstrated.

In the second part, a specific induction motor will be simulated and studied under time-harmonic FE analysis, taking into account the nonlinear magnetic characteristic of the stator and rotor iron core. Four different models will be created and studied, one with open stator slots and three more with different sized semimagnetic wedges closing the stator slot openings. Generally, it is proposed that the value of the relative magnetic permeability of the wedge material should be between 5 and 12. For all cases, in this work the relative magnetic permeability of the wedge material is considered equal to 10. The time-harmonic FEA will show that one of the three wedged motors has the best behavior.
In the third part of this work, the motor with open stator slots and the wedged one presenting the optimum behavior, resulting from the Time-harmonic Analysis, will be simulated at nominal load under transient FE analysis. The transient analysis will lead to the torque and stator current waveforms. The current and electromagnetic torque's harmonic contents will be shown with the application of the fast fourier transform (FFT).

The FEM analysis will reveal harmonic rank numbers which depend on the relative position between the stator and rotor and which cannot be predicted through analytical calculations. Furthermore, the electromagnetic variables of each model, such as electromagnetic torque, stator current, efficiency, and power factor, will be calculated and compared to each other.

\section{Analytical Calculation of the Harmonic Content of the Air-Gap Magnetic Flux Density Radial Component}

2.1. Calculation of the Magnetic Flux Density Harmonics. In previous work [29], it has been shown that the radial component of the air-gap magnetic flux density can be calculated by

$$
b(\alpha, t)=\left[F_{1}(\alpha, t)+F_{2}(\alpha, t)\right] \Lambda_{g}(\alpha, t)
$$

or if $b(\alpha, t)$ is divided into the stator and rotor MMF contribution to the magnetic flux density,

$$
b(\alpha, t)=b_{1}(\alpha, t)+b_{2}(\alpha, t)
$$

where

$$
b_{1}(\alpha, t)=b_{1}^{1}(\alpha, t)+b_{1}^{2}(\alpha, t)+b_{1}^{3}(\alpha, t)+b_{1}^{4}(\alpha, t)
$$

and each individual term of (3) is

$$
\begin{gathered}
b_{1}^{1}(\alpha, t)=\frac{\mu_{0}}{k_{C} g}\left[\sum_{v=6 \kappa \pm 1}^{\infty} F_{m \nu} \cos (v p \alpha \mp \omega t)\right], \\
b_{1}^{2}(\alpha, t)=\frac{1}{2} \frac{\mu_{0}}{k_{C} g} \sum_{v=6 \kappa \pm 1}^{\infty} \sum_{k=1,2,3}^{\infty} F_{m v} \mathrm{~A}_{k}\left\{\begin{array}{c}
\cos \left[\left(v p+k s_{1}\right) \alpha \mp \omega t\right]+ \\
\cos \left[\left(v p-k s_{1}\right) \alpha \mp \omega t\right]
\end{array}\right\}, \\
b_{1}^{3}=\frac{1}{2} \frac{\mu_{0}}{k_{C} g} \sum_{v=6 \kappa \pm 1}^{\infty} \sum_{l=1,2,3}^{\infty} F_{m v} \mathrm{~A}_{l}\left\{\begin{array}{c}
\cos \left[\left(v p+l s_{2}\right) \alpha-\left(l s_{2} \omega_{2} \pm \omega\right) t\right]+ \\
\cos \left[\left(v p-l s_{2}\right) \alpha+\left(l s_{2} \omega_{2} \mp \omega\right) t\right]
\end{array}\right\}, \\
b_{1}^{4}=\frac{1}{4} \frac{\mu_{0}}{k_{C} g} \sum_{\nu=6 \kappa \pm 1}^{\infty} \sum_{k=1,2,3}^{\infty} \sum_{l=1,2,3}^{\infty} F_{m v} \mathrm{~A}_{k} \mathrm{~A}_{l}\left\{\begin{array}{c}
\cos \left[\left(v p+l s_{2}+k s_{1}\right) \alpha-\left(l s_{2} \omega_{2} \pm \omega\right) t\right]+ \\
\cos \left[\left(v p-l s_{2}-k s_{1}\right) \alpha+\left(l s_{2} \omega_{2} \mp \omega\right) t\right]+ \\
\cos \left[\left(v p+l s_{2}-k s_{1}\right) \alpha-\left(l s_{2} \omega_{2} \pm \omega\right) t\right]+ \\
\cos \left[\left(v p-l s_{2}+k s_{1}\right) \alpha+\left(l s_{2} \omega_{2} \mp \omega\right) t\right]
\end{array}\right\}
\end{gathered}
$$


same for the rotor MMF contribution to the magnetic flux and each individual term of (5) is density term:

$$
b_{2}(\alpha, t)=b_{2}^{1}(\alpha, t)+b_{2}^{2}(\alpha, t)+b_{2}^{3}(\alpha, t)+b_{2}^{4}(\alpha, t)
$$

$$
\begin{gathered}
b_{2}^{1}(\alpha, t)=\frac{\mu_{0}}{k_{C} g}\left[\sum_{\mu=1}^{\infty} F_{m \mu} \cos (\mu p \alpha \mp \omega t-\varphi)\right], \\
b_{2}^{2}=\frac{1}{2} \frac{\mu_{0}}{k_{C} g} \sum_{\mu=1}^{\infty} \sum_{k=1,2,3}^{\infty} F_{m \mu} \mathrm{A}_{k}\left\{\begin{array}{c}
\cos \left[\left(\mu p+k s_{1}\right) \alpha \mp \omega t-\varphi\right]+ \\
\cos \left[\left(\mu p-k s_{1}\right) \alpha \mp \omega t-\varphi\right]
\end{array}\right\}, \\
b_{2}^{3}=\frac{1}{2} \frac{\mu_{0}}{k_{C} g} \sum_{\mu=1}^{\infty} \sum_{l=1,2,3}^{\infty} F_{m \mu} \mathrm{A}_{l}\left\{\begin{array}{l}
\cos \left[\left(\mu p+l s_{2}\right) \alpha-\left(l s_{2} \omega_{2} \pm \omega\right) t-\varphi\right]+ \\
\cos \left[\left(\mu p-l s_{2}\right) \alpha+\left(l s_{2} \omega_{2} \mp \omega\right) t-\varphi\right]
\end{array}\right\}, \\
b_{2}^{4}=\frac{1}{4} \frac{\mu_{0}}{k_{C} g} \sum_{\mu=1}^{\infty} \sum_{k=1,2,3}^{\infty} \sum_{l=1,2,3}^{\infty} F_{m \mu} \mathrm{A}_{k} \mathrm{~A}_{l}\left\{\begin{array}{l}
\cos \left[\mu p \alpha \mp \omega t-\varphi+\left(l s_{2}+k s_{1}\right) \alpha-l s_{2} \omega_{2} t\right]+ \\
\cos \left[\mu p \alpha \mp \omega t-\varphi-\left(l s_{2}+k s_{1}\right) \alpha+l s_{2} \omega_{2} t\right]+ \\
\cos \left[\mu p \alpha \mp \omega t-\varphi+\left(l s_{2}-k s_{1}\right) \alpha-l s_{2} \omega_{2} t\right]+ \\
\cos \left[\mu p \alpha \mp \omega t-\varphi+\left(l s_{2}-k s_{1}\right) \alpha+l s_{2} \omega_{2} t\right]
\end{array}\right\}
\end{gathered}
$$

From (4) the space harmonics of rank $v$ which depend on the stator MMF and the rotor and stator slot numbers $s_{1}, s_{2}$ are presented, respectively as follows:

$$
\left\{\begin{array}{c}
v p \\
v p \pm k s_{1} \\
v p \pm l s_{2} \\
v p \pm l s_{2} \pm k s_{1}
\end{array}\right\} \quad \forall v=6 \kappa \pm 1, \kappa, k, l \in \mathbb{N}
$$

Considering that the motor examined has 36 stator slots and 28 rotor slots and 4 poles, (7) is transformed into

$$
\left\{\begin{array}{c}
v, \\
v \pm 2 k^{\prime}, \\
v \pm 2 l^{\prime}, \\
v \pm 2\left(k^{\prime} \pm l^{\prime}\right)
\end{array}\right\} \quad \forall v=6 \kappa \pm 1, k^{\prime}=9 k, l^{\prime}=7 l, \kappa, k, l \in \mathbb{N} .
$$

Also, from (6) the space harmonics ranks depending on the rotor MMF and the rotor and stator slot numbers are presented, respectively as follows:

$$
\left\{\begin{array}{c}
\mu, \\
\mu \pm 2 k^{\prime}, \\
\mu \pm 2 l^{\prime}, \\
\mu \pm 2\left(k^{\prime} \pm l^{\prime}\right)
\end{array}\right\} \quad \forall k^{\prime}=9 k, l^{\prime}=7 l, \mu=14 k \pm 1, k, l \in \mathbb{N}
$$

From (8) and (9) the air-gap magnetic flux density harmonic content, related to the number of stator and rotor slots and the motor's magnetic poles, is presented. Due to the fact that the motor used for this research, both the numbers of stator and rotor slots are multiples of 4 and the number of poles is also 4 , the harmonic ranks occur to be odd numbers. If the examined motor had two poles, it would present both even and odd harmonic rank numbers in the air-gap magnetic flux density waveform.

2.2. Calculation of Saturation Harmonics. According to [30, 31] the air-gap relative permeance takes the following form in order to take into account the iron core saturation, considering the fundamental harmonic:

$$
\Lambda(\alpha) \approx \Lambda_{0}+\Lambda_{\text {sat }}(\alpha, t)
$$

where

$$
\Lambda_{\text {sat }}(\alpha, t)=-\Lambda_{\text {sat }} \cos \left(2 p \alpha-2 \omega_{1} t-2 \varphi_{s}\right) .
$$

So, the influence of the rotor and stator MMF on the magnetic flux density, due to the saturation will be

$$
b_{\text {sat }}(\alpha, t)=\left[F_{1}(\alpha, t)+F_{2}(\alpha, t)\right] \Lambda_{\text {sat }}(\alpha, t) .
$$

Equation (12) due to (11) results to the following:

$$
b_{\text {sat }}(\alpha, t)=-\Lambda_{\text {sat }} \frac{1}{2}\left[\begin{array}{c}
\sum_{\nu=6 \kappa \pm 1}^{\infty} F_{m \nu}\left\{\begin{array}{c}
\cos \left[(v+2) p \alpha-\left(2 \omega_{1} \pm \omega\right) t-2 \varphi_{s}\right]+ \\
\cos \left[(v-2) p \alpha+\left(2 \omega_{1} \mp \omega\right) t+2 \varphi_{s}\right]
\end{array}\right\}+ \\
\sum_{\mu=1}^{\infty} F_{m \mu}\left\{\begin{array}{c}
\cos \left[(\mu+2) p \alpha-\left(2 \omega_{1} \pm \omega\right) t-\left(\varphi+2 \varphi_{s}\right)\right]+ \\
\cos \left[(\mu-2) p \alpha+\left(2 \omega_{1} \mp \omega\right) t-\left(\varphi-2 \varphi_{s}\right)\right]
\end{array}\right\}
\end{array}\right] .
$$




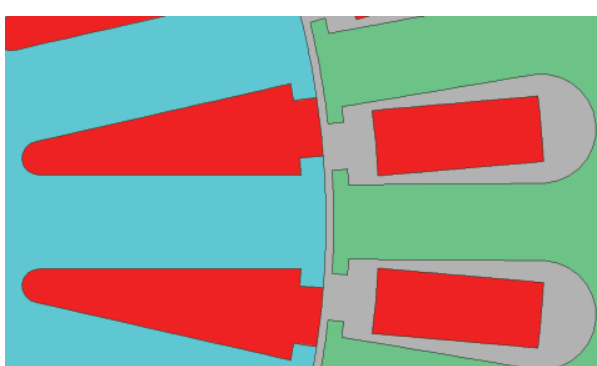

(a)

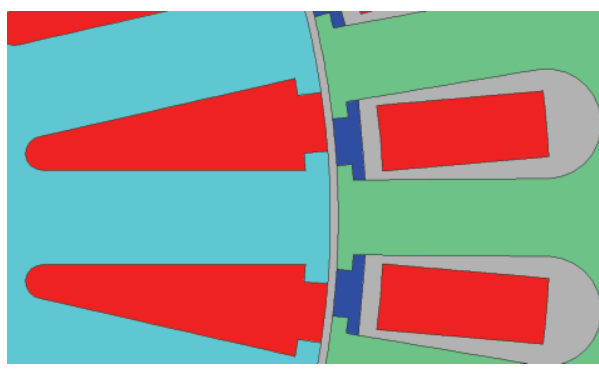

(c)

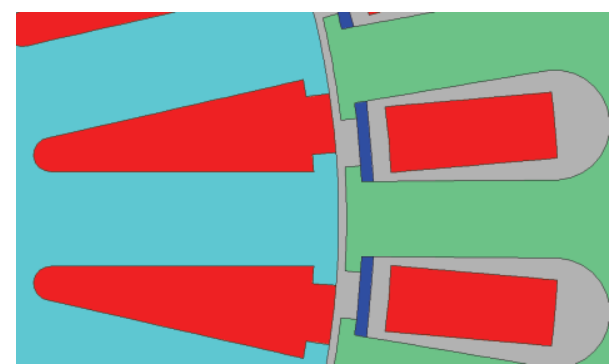

(b)

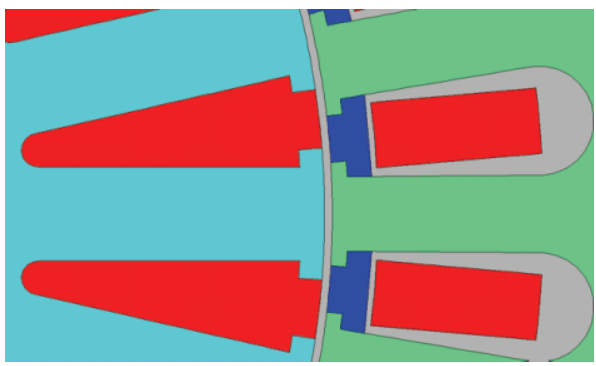

(d)

FIgURE 1: The four simulated models: (a) original, (b) w-A, (c) w-B, and (d) w-C.

From (13) one may observe that the harmonic ranks of the air-gap magnetic flux density due to saturation, obey the following:

$$
\left\{\begin{array}{l}
(v \pm 2), \\
(\mu \pm 2)
\end{array}\right\} \quad \forall v=6 \kappa \pm 1, \mu=14 k \pm 1, \kappa \in \mathbb{N} \text {. }
$$

From (8), (9), and (14), occurs that harmonic numbers such as 3,5 , and 9 are produced from both the stator slots existence and the iron core magnetic saturation. Furthermore, the analytical solution leads to the result that the space harmonic rank of the air-gap magnetic flux density due to saturation is always an odd number, as expected.

2.3. The Electromagnetic Torque Harmonics. In [32], the formula which predicts the electromagnetic torque timedependent harmonic content is described by (15) as follows:

$$
\left[ \pm \nu \pm l \cdot s_{2}\left(\frac{1-s}{p}\right) \pm 2 \kappa^{\prime} \pm \mu\right] f_{s}
$$

where $v$ is the stator MMF harmonic rank number, $\mu$ is the rotor MMF harmonic rank number, $l=1,2,3, \ldots$ is the rotor slot-related harmonic rank number, $\kappa^{\prime}=1$ or 0 , when considering or not the effect of saturation, respectively.

\section{FEM Analysis and Results}

3.1. Creating the FEM Models. The induction motor used for this research is a 3 -phase, $4 \mathrm{~kW}, 400 \mathrm{~V}$, with 28 rotor slots and 36 stator slots, 4-pole induction squirrel-cage motor. The stator phase resistance was measured in the laboratory through DC current injection. Also, for the analysis the nonlinear magnetic B-H characteristic is taken into consideration, extracted from the manufacturer data sheets. Four models have been simulated and studied. The original model with open stator slots and three more with different sized semimagnetic wedges closing the stator slot openings. The wedge material has a linear B-H characteristic and the relative magnetic permeability is considered equal to 10 . For each of these three models, wedges of different size are applied. In Figure 1 the four models' slot openings are presented. In the case of wedge- $\mathrm{A}$, the wedge is inside the stator slot without totally filling the stator slot opening. Moreover, in the cases of wedge- $\mathrm{B}$ and wedge- $\mathrm{C}$, the wedge totally closes the stator slot opening but also the wedge- $\mathrm{C}$ covers double depth inside the stator slot compared to wedge- $\mathrm{B}$ model. From now on, the four models will be referred to as original, $\mathrm{w}-\mathrm{A}, \mathrm{w}-\mathrm{B}$ and $\mathrm{w}-\mathrm{C}$, respectively.

3.2. Comparison of the Static Characteristics. The models have been simulated under time-harmonic analysis. For each model the electromagnetic torque, stator current amplitude, efficiency, and power factor for speed values between 0 and synchronous speed have been extracted. In Figures 2 and 3 , the torque and the stator current amplitude versus speed characteristics of the $\mathrm{w}-\mathrm{A}, \mathrm{w}-\mathrm{B}$ and $\mathrm{w}-\mathrm{C}$ models are presented, respectively, and compared to the original model's characteristics. Moreover, in Table 1, the starting torque and 
TABLE 1: Simulation results at starting and at $1470 \mathrm{rpm}$.

\begin{tabular}{lcccccc}
\hline Model & Starting torque $(\mathrm{Nm})$ & Starting current $(\mathrm{A})$ & Torque at $1470 \mathrm{rpm}(\mathrm{Nm})$ & Current at $1470 \mathrm{rpm}(\mathrm{Nm})$ & $\eta(\%)$ & $\cos \varphi(\%)$ \\
\hline Original & 83.02 & 65.86 & 26.07 & 7.13 & 82.67 & 84.34 \\
w-A & 73.70 & 61.85 & 25.36 & 6.96 & 84.34 & 82.41 \\
w-B & 70.60 & 60.70 & 24.59 & 6.76 & 85.70 \\
w-C & 63.68 & 57.99 & 23.94 & 6.59 & 81.05 \\
\hline
\end{tabular}

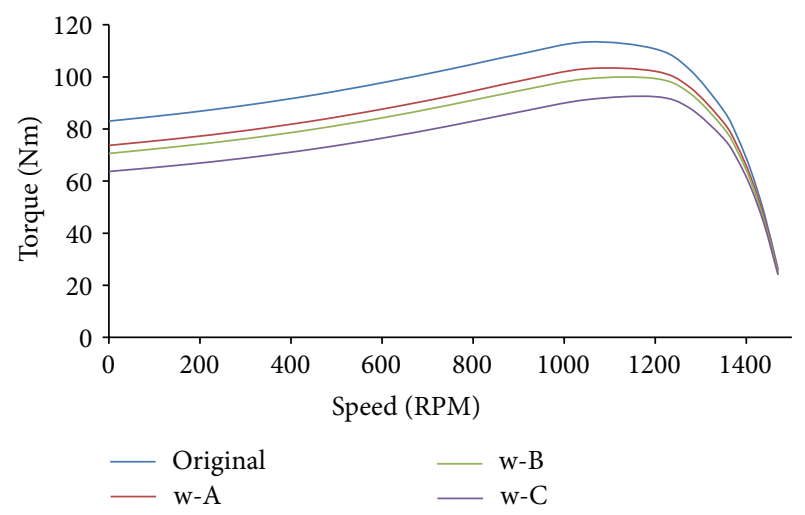

FIGURE 2: Electromagnetic torque versus speed for the four simulated motors.

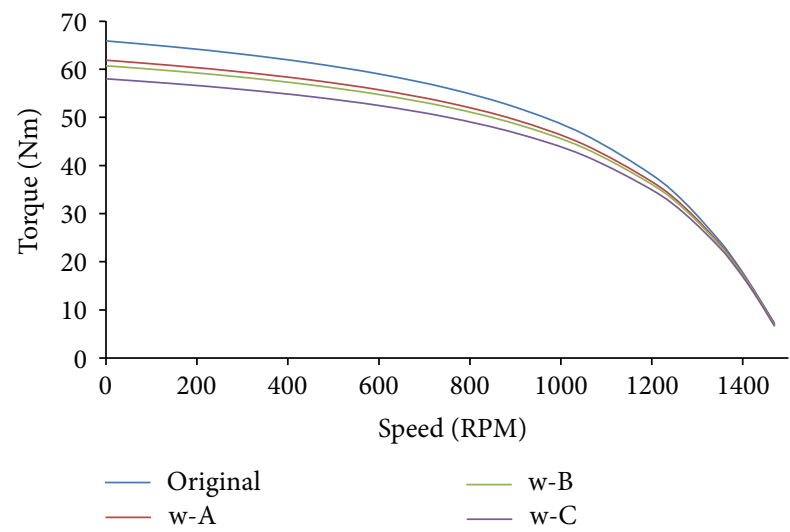

FIGURE 3: Stator current amplitude versus speed for the four simulated motors.

stator current, as well as the torque, stator current, efficiency $\eta$, and power factor at $1470 \mathrm{rpm}$ are presented.

The use of semimagnetic wedges decreases the electromagnetic torque and the stator current amplitude, for every speed. In this work, the wedge material is considered linear due to its low relative magnetic permeability. So, as a result, the starting torque of the motors, where wedges are applied, is lower than the original model's, due to the increased leakage flux.

At $1470 \mathrm{rpm}$, the stator current and as a consequence the electromagnetic torque of the models with wedges decrease with the increment of the wedge size, compared to the original. The same observation stands for the power factor due to the increase of the leakage flux. Nevertheless, the efficiency of $\mathrm{w}-\mathrm{A}, \mathrm{w}-\mathrm{B}$, and $\mathrm{w}-\mathrm{C}$ models is about $1.7 \%, 3 \%$ and
$4.1 \%$ greater than the original's, respectively. The above results will be explained later in this paper, through the study of the air-gap magnetic flux density harmonic content occurring from the analytical calculations and FEM analysis.

3.3. Fourier Analysis of the Spatial Air-Gap Magnetic Flux Density Radial Component at Nominal Speed. In Figure 4, the normalized amplitude of the magnetic flux density radial component in $\mathrm{dB}$ in the middle of the air-gap versus the harmonic rank number is presented for the four simulated models, at nominal speed. By observing the harmonic content of the models, one can see that even number harmonics are reduced in every case where semimagnetic wedges are used. Even rank harmonics carry the information of the instant relative position of the rotor and can be observed through FEM, while they are very difficult to be predicted through the analytical approach. In the case of $\mathrm{w}-\mathrm{B}$ model, the even harmonics are reduced the most compared to the other two models. In the case of $\mathrm{w}$ - $\mathrm{C}$ model the even rank harmonic content is much decreased compared to w-A model but slightly increased compared to w-B model.

Furthermore, as mentioned previously through the analytical calculations (14), harmonics 3, 5, and 9 are of great importance because they offer information about the saturation of the iron core and more specifically of the tooth tips. The original model presents the $3 \mathrm{rd}$ harmonic at $-32 \mathrm{~dB}$, the 5 th at $-25 \mathrm{~dB}$, and the 9 th at $-30 \mathrm{~dB}$. Compared to the original, the $\mathrm{w}-\mathrm{A}$ model presents the $3 \mathrm{rd}$ harmonic at $-41 \mathrm{~dB}$, the 5 th at $-39 \mathrm{~dB}$, and the 9 th at $-45 \mathrm{~dB}$. The $\mathrm{w}-\mathrm{B}$ model presents the $3 \mathrm{rd}$ harmonic at $-50 \mathrm{~dB}$, the 5 th also at $-39 \mathrm{~dB}$ and the 9 th at $-58 \mathrm{~dB}$. Finally, the $\mathrm{w}-\mathrm{C}$ model presents the $3 \mathrm{rd}$ harmonic at $-40 \mathrm{~dB}$, the 5 th harmonic, like the original model, at $-25 \mathrm{~dB}$, and the 9 th at $-38 \mathrm{~dB}$. To sum up, saturation has decreased while passing from the original model to $\mathrm{W}$ A model, continues to decrease in the $\mathrm{w}-\mathrm{B}$ model and then in the model $\mathrm{w}-\mathrm{C}$ increases again. The increase of the iron saturation in the $\mathrm{w}-\mathrm{C}$ model makes perfect sense if one takes into consideration that the leakage flux in this model has increased due to the greater depth of the semimagnetic wedge in $\mathrm{w}-\mathrm{C}$ model.

Moreover, from (8) and (9), different combinations between the variables $v, \mu, k$ and $l$ lead to the slot-related space harmonic ranks. Slot-related harmonic rank number can be any odd number. So, slot harmonics contribute to the stator and rotor MMF related harmonics, since they are presented at the same rank numbers. From Figure 4 one can see that the stator MMF related harmonics, such as 5, 7, 11, and 13 and so forth, present significantly lower amplitudes in the case of $\mathrm{w}-\mathrm{A}$ and $\mathrm{w}-\mathrm{B}$ models compared to the original. 


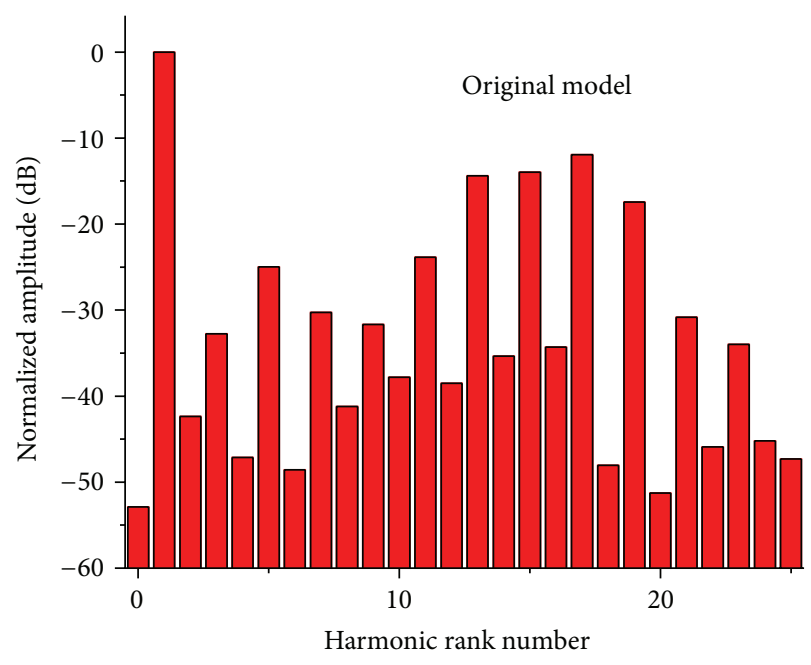

(a)

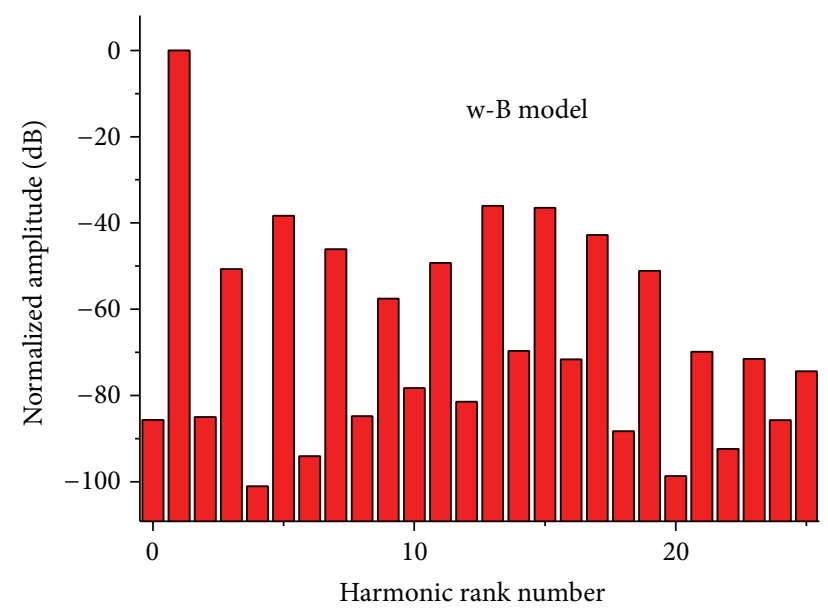

(c)

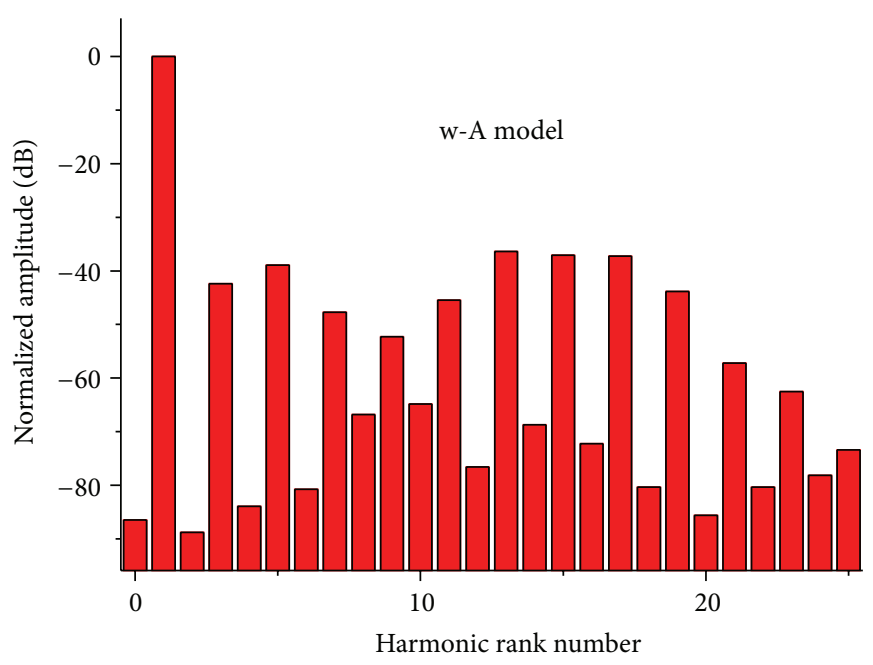

(b)

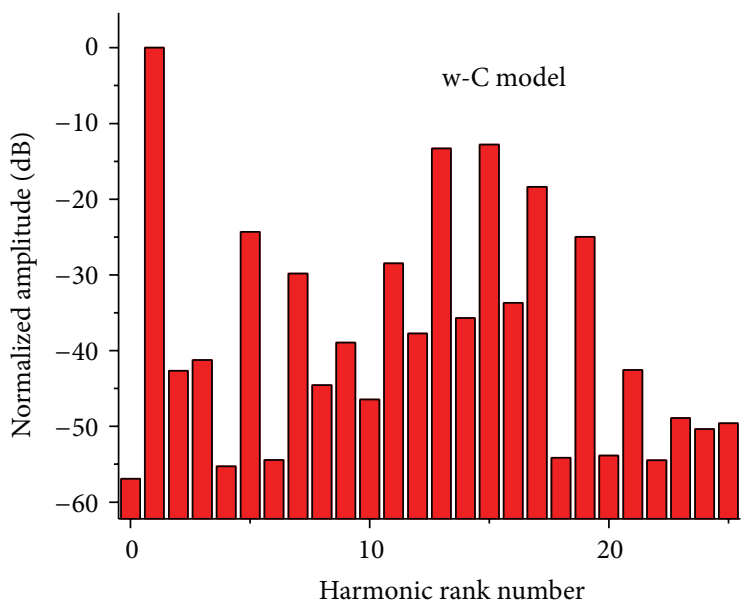

(d)

Figure 4: Normalized amplitude of the air-gap magnetic flux density at $1470 \mathrm{rpm}$ for the cases: (a) original model, (b) w-A model, (c) w-B model and (d) w-C model.

The same harmonics for the $\mathrm{w}$-C model do not seem to have any important difference compared to the model with open slots, except the harmonics with ranks 17 and 19 that have been both decreased about $5 \mathrm{~dB}$. Furthermore, the harmonic rank 15 is related to the rotor MMF as shown previously in (4). This harmonic, in the models $\mathrm{w}-\mathrm{A}$ and $\mathrm{w}-\mathrm{B}$, has an amplitude equal to $-38 \mathrm{~dB}$, whereas for the same rank number, the amplitude occurs $-14 \mathrm{~dB}$ for the original and the $\mathrm{w}$-C models.

The harmonic content of the simulated models, presented in Figure 4, indicates that the use of semimagnetic wedges has a strong impact on the even number harmonics of the magnetic field, related to the asymmetry of the air-gap induced by the relative position between rotor and stator, as mentioned in the previous paragraph. The air-gap radial component of the magnetic flux density is improved when wedges are implemented. Moreover, $\mathrm{w}-\mathrm{B}$ and $\mathrm{w}-\mathrm{C}$ models both result in a strong decrease of the air-gap magnetic flux density higher harmonic content because of the shape of the wedge, which fully covers the stator slot opening.
TABLE 2: THD-amplitude ratio at nominal speed.

\begin{tabular}{lc}
\hline Model & THD (\%) \\
\hline Original & 49.23 \\
w-A model & 48.35 \\
w-B model & 40.41 \\
w-C model & 41.03 \\
\hline
\end{tabular}

For each case, the Total Harmonic Distortion-amplitude ratio (THD) was also calculated until rank number 50, at nominal speed for better comparison between the simulated models. The results are presented in Table 2. The w-A model's THD decreases less than $1 \%$ compared to the original, while w-B model's THD decreases about $9 \%$. Moreover, it is obvious that the $\mathrm{w}$-C model's THD is $8 \%$ lower than the original's but also slightly increased compared to the w-B model.

The $\mathrm{w}-\mathrm{B}$ model is characterized by the greatest reduction of the air-gap magnetic flux density harmonic content. 


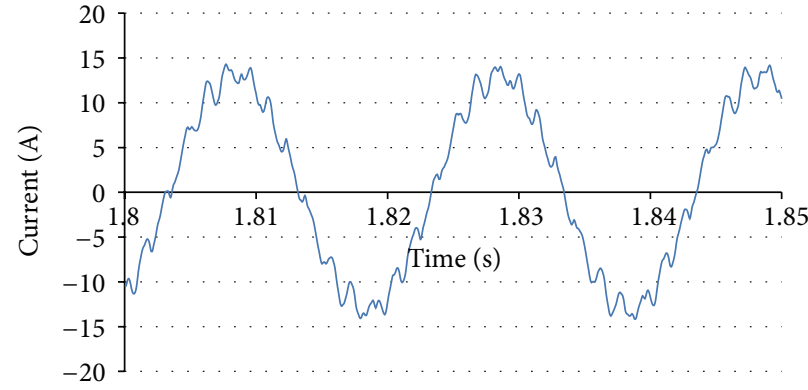

(a)

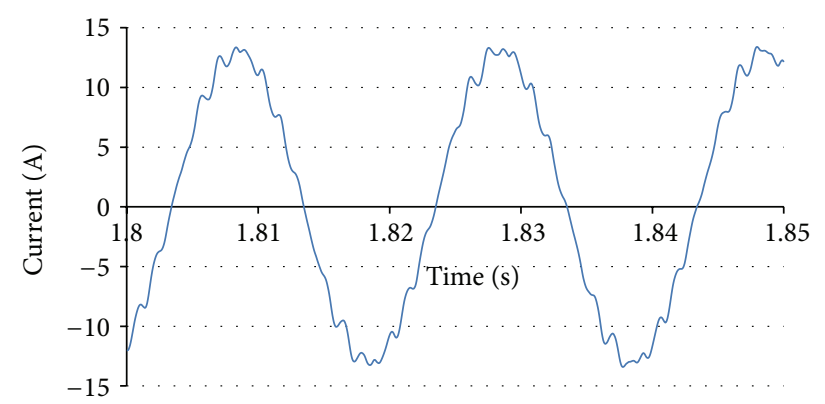

(b)

Figure 5: The line current waveforms for: (a) the original and (b) the w-b models.

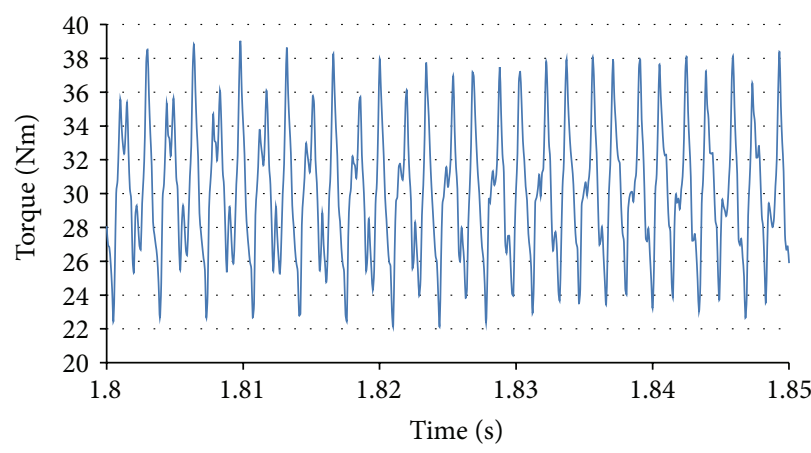

(a)

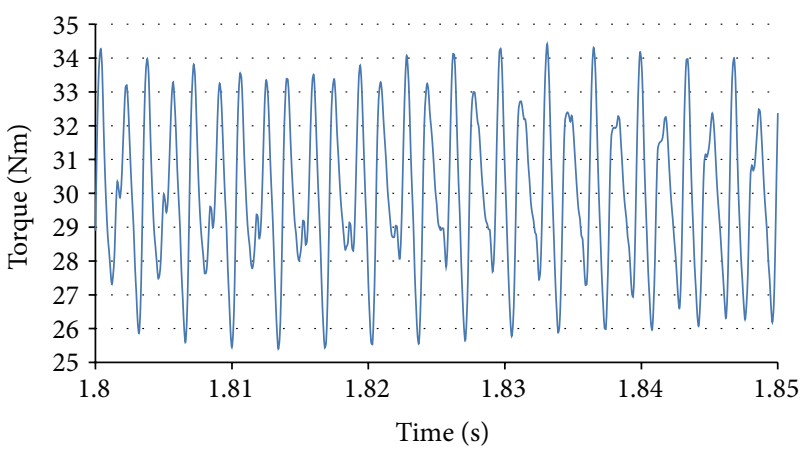

(b)

FIGURE 6: The torque waveforms for (a) the original and (b) the w-b models.

Also, it presents greater starting electromagnetic torque and slightly increased starting stator current than the $\mathrm{w}-\mathrm{C}$ model. Moreover, it proves to have greater efficiency than w-A model and greater power factor than $\mathrm{w}-\mathrm{C}$ model at nominal speed. On the other hand, its power factor is reduced compared to wA model and its efficiency is less than that of $\mathrm{w}-\mathrm{C}$ model. From all of the above, the $\mathrm{w}-\mathrm{B}$ model presents an average satisfying behavior at starting and at nominal speed at the same time, compared to the w-A and $\mathrm{w}-\mathrm{C}$ models.

\section{Transient FEM Analysis under Nominal Load}

In this paragraph, two models, the original and $\mathrm{w}-\mathrm{B}$, will be simulated and studied under transient Rotating Machine (RM) analysis at the same load $30 \mathrm{Nm}$. Same as in timeharmonic analysis, shown in the previous paragraph, the analysis will take into account the nonlinear magnetic B-H characteristic of the stator and rotor iron core.

In Figures 5 and 6 , one can see the line current and the torque waveforms, respectively, for the original and $\mathrm{w}$ $\mathrm{B}$ motors. It seems that both signals are smoother when the wedges are applied. Also, the torque ripple has been decreased.

The frequency spectrums of the line current and torque signals are presented in Figure 7, for the cases of the original and w-b models. In both spectrums (Figures 7(a) and 7(b)),
TABLE 3: Line current rotor slot-related harmonics amplitudes.

\begin{tabular}{lccc}
\hline $\begin{array}{l}\text { Harmonic } \\
(\mathrm{Hz})\end{array}$ & Open slots $(\mathrm{dB})$ & Harmonic $(\mathrm{Hz})$ & Wedged $(\mathrm{dB})$ \\
\hline 20 & $-50,86$ & 22,31 & $-57,18$ \\
80 & $-50,86$ & 77,69 & $-58,15$ \\
333,8 & $-52,26$ & 332,3 & $-59,85$ \\
633,8 & $-21,69$ & 632,3 & $-27,81$ \\
603,8 & $-62,91$ & 604,6 & $-75,56$ \\
663,1 & $-62,76$ & 660 & $-75,47$ \\
\hline
\end{tabular}

the location of rotor slot-related harmonics is shown with arrows. Those harmonics are produced by the component $l s_{2} \omega_{2}$, which can be found in (4), (6), and (15). The harmonics' amplitudes of the marked frequencies of Figure 7 are presented in Tables 3 and 4. It is clear that, the wedges application strongly reduces the rotor slot-related harmonics.

\section{Conclusions}

In this work, the influence of different sized semimagnetic wedges on the air-gap magnetic field harmonic content and the electromagnetic characteristics of the induction motor was investigated through analytical equations and FEM analysis. The results indicate that the use of semimagnetic wedges leads to the decrease of the air-gap magnetic field 


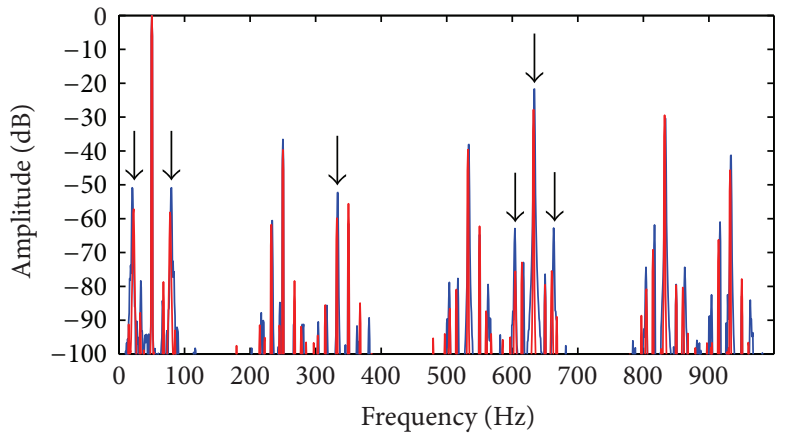

(a)

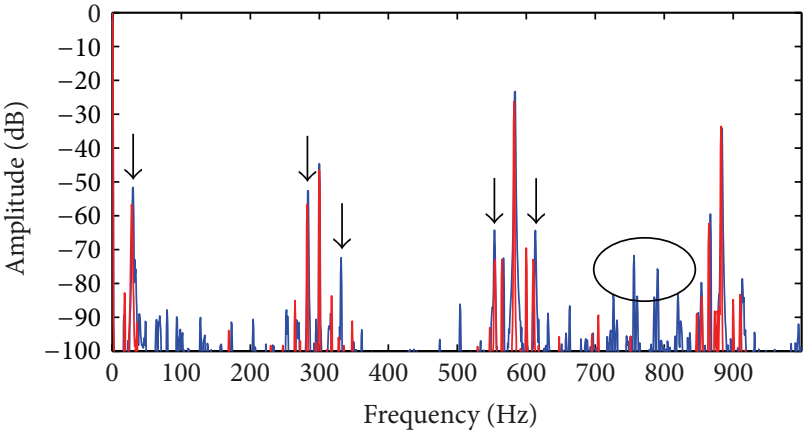

(b)

FIGURE 7: Frequency spectrum of the original (blue) and w-b (red) models of the (a) line current and (b) torque.

TABLE 4: Torque rotor slot-related harmonics amplitudes.

\begin{tabular}{lccc}
\hline Harmonic $(\mathrm{Hz})$ & Open slots $(\mathrm{dB})$ & Harmonic $(\mathrm{Hz})$ & Wedged $(\mathrm{dB})$ \\
\hline 30 & $-51,63$ & 27,69 & $-56,76$ \\
283,1 & $-52,71$ & 282,3 & $-56,56$ \\
331,5 & $-72,39$ & 327,7 & $-95,95$ \\
553,8 & $-64,25$ & 554,6 & $-73,02$ \\
613,1 & $-64,34$ & 610 & $-72,93$ \\
\hline
\end{tabular}

harmonic content, which is also influenced by the wedge geometry. The $\mathrm{w}-\mathrm{B}$ model presented the least THD of its airgap magnetic flux density at nominal speed, as well as an average satisfying behavior at starting and nominal speed at the same time. For the above reasons, the $\mathrm{w}-\mathrm{B}$ model was selected to be studied and compared to the original one, under transient FEA operating at nominal load. The timedependent harmonic content of both the electromagnetic torque and the stator current has been significantly reduced in the case of the wedged model compared to the one with open slots. This behavior leads to slightly lower output power at nominal speed and lower power factor, but, on the other hand improvement of the motor's efficiency and lower stator current at nominal speed. Finally, this work's results state that the geometry of the wedge is crucial, since it determines the electromagnetic variables and behaviour of the induction motor.

\section{Nomenclature}

a: $\quad$ Geometrical angle

$\lambda_{g 1}, \lambda_{g 2}:$ Component of the air-gap relative specific permeance varying with the angle $\alpha$ when only the stator and rotor, respectively, are slotted

$\tau: \quad$ Stator slot pitch

$\omega: \quad$ Stator angular frequency

$\omega_{2}: \quad$ Rotor angular frequency

$\Lambda_{g}: \quad$ Air-gap relative permeance

$\Lambda_{\text {sat }}: \quad$ Air-gap relative permeance saturation component

$\Omega_{m}: \quad$ Mechanical angular frequency $b, b_{1}, b_{2}$ : Total, stator and rotor air-gap magnetic flux density radial components

$f: \quad$ Stator frequency

$g: \quad$ Air-gap length

$k_{c}: \quad$ Carter's coefficient

$n_{s}: \quad$ Synchronous speed

$p: \quad$ Number of pole pairs

q: $\quad$ Number of stator slots per phase and pole

$s: \quad$ Slip

$s_{1}, s_{2}: \quad$ Stator and rotor slot numbers, respectively

$F_{1}, F_{2}: \quad$ Stator and rotor MMF, respectively

$F_{m v}, F_{m \mu}:$ Stator and rotor MMF amplitude, respectively.

\section{Acknowledgment}

This work has been supported by the research program: "K. Karatheodori 2010," of the Research Committee of the University of Patras, Greece.

\section{References}

[1] J. F. Gierras, C. Wang, and J. C. Lai, Noise of Polyphase Electric Motors, CRC Press, Taylor \& Francis Group, London, UK, 2006.

[2] M. Amrhein and P. T. Krein, "Induction machine modeling approach based on 3-D magnetic equivalent circuit framework," IEEE Transactions on Energy Conversion, vol. 25, no. 2, pp. 339$347,2010$.

[3] E. Laroche and M. Boutayeb, "Identification of the induction motor in sinusoidal mode," IEEE Transactions on Energy Conversion, vol. 25, no. 1, pp. 11-19, 2010.

[4] D. Wu and S. D. Pekarek, "A multirate field construction technique for efficient modeling of the fields and forces within inverter-fed induction machines," IEEE Transactions on Energy Conversion, vol. 25, no. 1, pp. 217-227, 2010.

[5] R. M. Rosas, O. B. Aragonès, X. C. Fajula, and A. R. Blanco, "Behavior of the three-phase induction motor with spiral sheet rotor," IEEE Transactions on Energy Conversion, vol. 24, no. 1, pp. 68-76, 2009.

[6] K. Delaere, R. Belmans, and K. Hameyer, "Influence of rotor slot wedges on stator currents and stator vibration spectrum of induction machines: a transient finite-element analysis," IEEE Transactions on Magnetics, vol. 39, no. 3, pp. 1492-1494, 2003. 
[7] R. K. S. Chitroju and C. Sadarangani, "Design and analysis of asymmetrical rotor for induction motors," in Proceedings of the International Conference on Electrical Machines (ICEM '08), September 2008.

[8] K. Gyftakis, J. Kappatou, and A. Safacas, "FEM study of asynchronous cage motors combining NEMA's classes A and D slot geometry," in Proceedings of the 19th International Conference on Electrical Machines (ICEM '10), Rome, Italy, September 2010.

[9] R. Carlson, C. A. da Silva, N. Sadowski, Y. Lefèvre, and M. Lajoie-Mazenc, "The effect of the stator-slot opening on the interbar currents of skewed cage induction motor," IEEE Transactions on Magnetics, vol. 38, no. 2, pp. 1285-1288, 2002.

[10] A. Kaga, Y. Anazawa, H. Akagami, S. Watabe, and M. Makino, "A research of efficiency improvement by means of wedging with soft ferrite in small induction motors," IEEE Transactions on Magnetics, vol. 18, no. 6, pp. 1547-1549, 1982.

[11] G. H. Jang and S. J. Park, "Characterization of a single-phase induction motor due to the effect of slot opening," IEEE Transactions on Magnetics, vol. 40, no. 4, pp. 2065-2067, 2004.

[12] S. Wang, Z. Zhao, L. Yuan, and B. Wang, "Investigation and analysis of the influence of magnetic wedges on high voltage motors performance," in Proceedings of the IEEE Vehicle Power and Propulsion Conference (VPPC '08), Harbin, China, September 2008.

[13] R. Curiac and H. Li, "Improvements in energy efficiency of induction motors by the use of magnetic wedges," in Proceedings of the 58th Annual IEEE Petroleum and Chemical Industry Conference (PCIC '11), pp. 1-6, Toronto, Canada, September 2011.

[14] H. Mikami, K. Ide, K. Arai, M. Takahashi, and K. Kajiwara, "Dynamic harmonic field analysis of a cage type induction motor when magnetic slot wedges are applied," IEEE Transactions on Energy Conversion, vol. 12, no. 4, pp. 337-343, 1997.

[15] Y. Anazawa, A. Kaga, and H. Akagami, "Characteristics and carter's coefficient of small induction motors with ferrite magnetic wedges," Electrical Engineering in Japan, vol. 104, no. 2, pp. 94-101, 1984.

[16] M. Takahashi, M. Watanabe, K. Arai, and N. Takahashi, "Fundamental electromagnetic characteristics of magnetically anisotropic damper-wedges," Electrical Engineering in Japan, vol. 113, no. 2, pp. 121-130, 1993.

[17] J. Kappatou, C. Gyftakis, and A. Safacas, "A study of the effects of the stator slots wedges material on the behavior of an induction machine," in Proceedings of the International Conference on Electrical Machines (ICEM '08), Villamoura, Portugal, September 2008.

[18] J. Kappatou, K. N. Gyftakis, and A. N. Safacas, "Investigation of the stator semi-magnetic wedges influences on the behaviour of a cage asynchronous motor through time stepping finite element analysis," International Review of Electrical Engineering, vol. 6, no. 1, pp. 285-291, 2011.

[19] K. N. Gyftakis, P. Panagiotou, and J. Kappatou, “The influence of semi-magnetic wedges on the electromagnetic variables and the harmonic content in induction motors," in Proceedings of the 20th International Conference on Electrical Machines (ICEM '12), Marseille, France, September 2012.

[20] G. Madescu, M. Greconici, M. Biriescu, and M. Mot, "Effects of stator slot magnetic wedges on the induction motor performances," in Proceedings of the 13th International Conference on Optimization of Electrical and Electronic Equipment (OPTIM '12), pp. 489-492, Brasov, Romania, May 2012.
[21] M. Dems, K. Komeza, and J. K. Sykulski, "Analysis of effects of magnetic slot wedges on characteristics of large induction motors," in Proceedings of the 15th International Symposium on Electromagnetic Fields in Mechatronics, Electrical and Electronic Engineering (ISEF '11), Funchal, Portugal, September 2011.

[22] Y. Anazawa, A. Kaga, H. Akagami, S. Watabe, and M. Makino, "Prevention of harmonic torques in squirrel cage induction motors by means of soft ferrite magnetic wedges," IEEE Transactions on Magnetics, vol. 18, no. 6, pp. 1550-1552, 1982.

[23] S. Salon, D. Burow, M. DeBortoli, and C. Slavik, "Effects of slot closure and magnetic saturation on induction machine behavior," IEEE Transactions on Magnetics, vol. 30, no. 5, pp. 3697-3700, 1994.

[24] G. Stojcic, M. Vasak, N. Peric, G. Joksimovic, and T. M. Wolbank, "Detection of partially fallen-out magnetic slot wedges in inverter fed AC machines under various load conditions," in Proceedings of the IEEE Energy Conversion Congress \& Exposition (ECCE '12), Raleigh, NC, USA, September 2012.

[25] G. Stojcic, R. Magnet, J. Gojko, M. Vasak, N. Peric, and T. M. Wolbank, "Detecting partially fallen-out magnetic slot wedges in AC machines based on electrical quantities only," in Proceedings of the 38th Annual Conference on IEEE Industrial Electronics Society (IECON '12), pp. 3887-3892, Montreal, Canada, October 2012.

[26] T. R. Gaerke and D. C. Hernandez, "The temperature impact of magnetic wedges on TEFC induction motors," in Proceedings of the Annual IEEE Pulp and Paper Industry Technical Conference (PPIC '12), pp. 1-6, Portland, Ore, USA, June 2012.

[27] J. le Besnerais, V. Lanfranchi, M. Hecquet, and P. Brochet, "Optimal slot numbers for magnetic noise reduction in variablespeed induction motors," IEEE Transactions on Magnetics, vol. 45, no. 8, pp. 3131-3136, 2009.

[28] J. le Besnerais, V. Lanfranchi, M. Hecquet, R. Romary, and P. Brochet, "Optimal slot opening width for magnetic noise reduction in induction motors," IEEE Transactions on Energy Conversion, vol. 24, no. 4, pp. 869-874, 2009.

[29] K. N. Gyftakis and J. Kappatou, "The impact of the rotor slot number on the behaviour of the induction motor," Advances in Power Electronics, vol. 2013, Article ID 837010, 9 pages, 2013.

[30] H. Frohne, Über die Primären Bestimmungsgrößen der Lautstärke bei Asynchronmaschinen [Ph.D. dissertation], Technische Hochschule Hannover, Hannover, Germany, 1959.

[31] M. Purkemani, Beitrag zur Erfassung der Sättigungsoberfelder in Drehstromasynchromaschinen [Ph.D. thesis], Fakultät für Maschinenwesen, Technischen Hochschule Hannover, Hannover, Germany, 1971.

[32] K. N. Gyftakis, D. V. Spyropoulos, J. Kappatou, and E. D. Mitronikas, "A novel approach for broken bar fault diagnosis in induction motors through torque monitoring," IEEE Transactions on Energy Conversion, vol. 28, no. 2, pp. 267-277, 2013. 

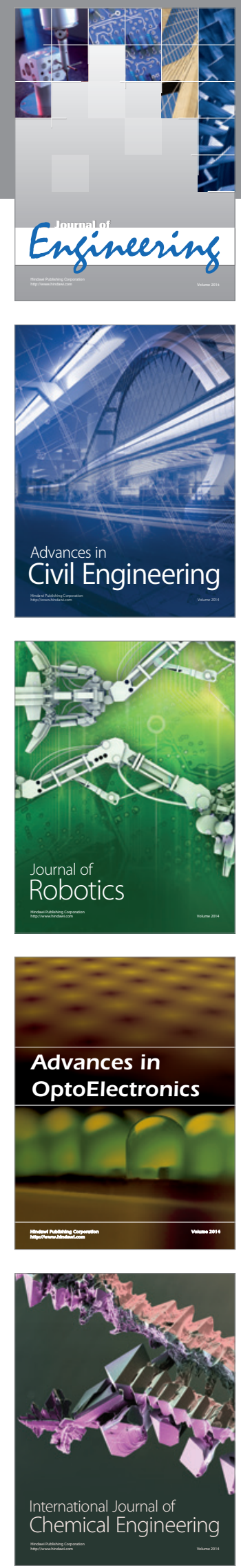

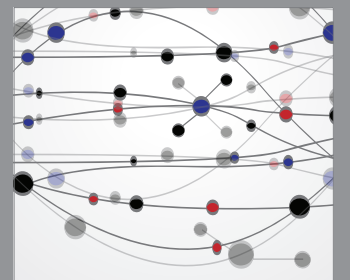

The Scientific World Journal
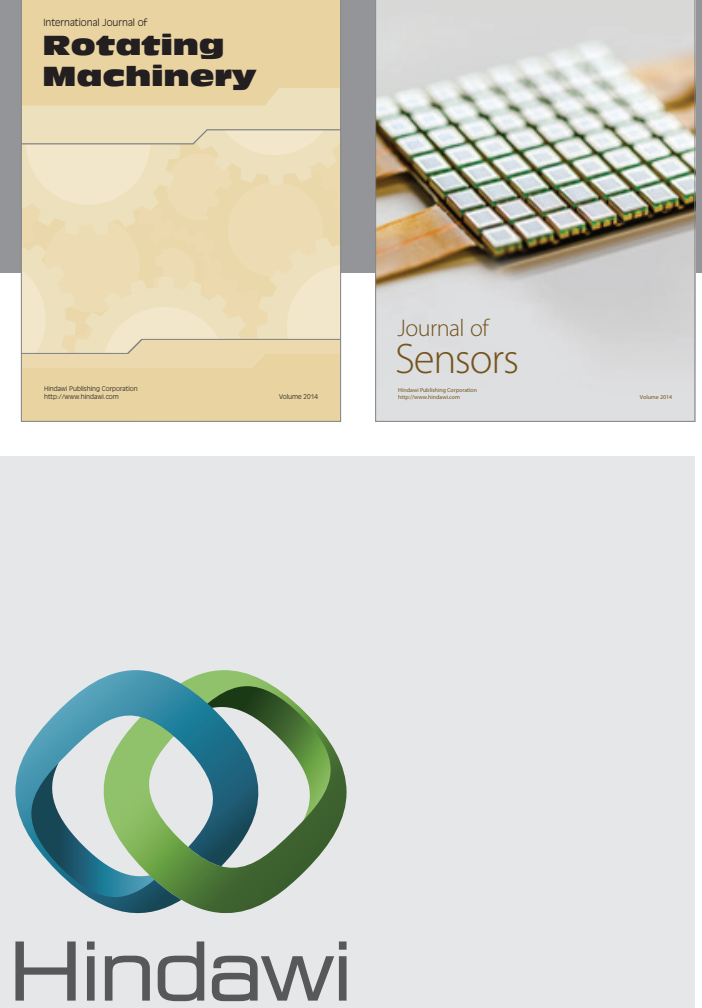

Submit your manuscripts at http://www.hindawi.com
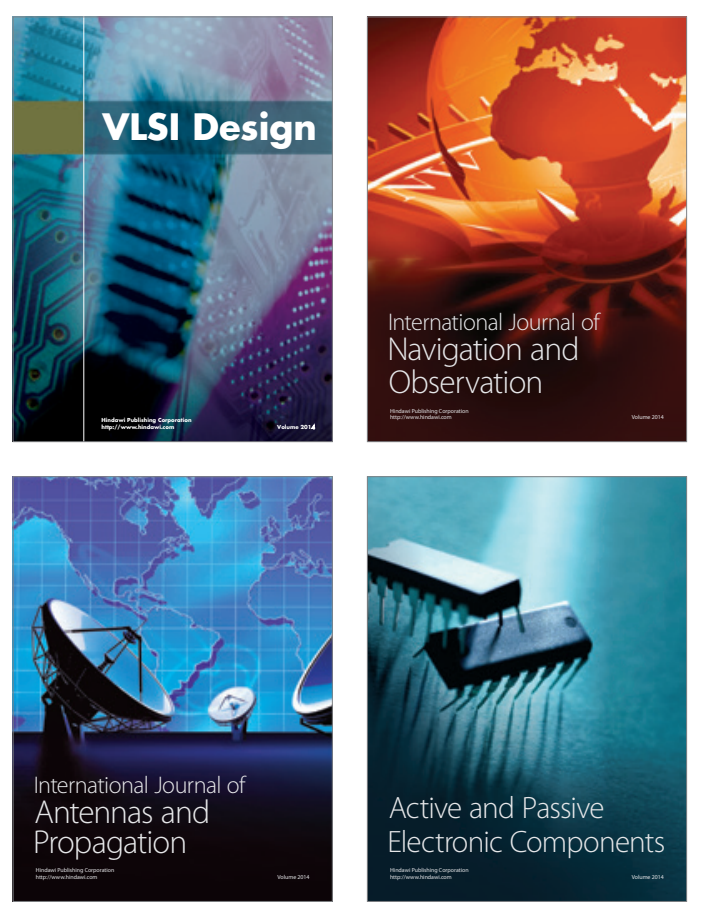
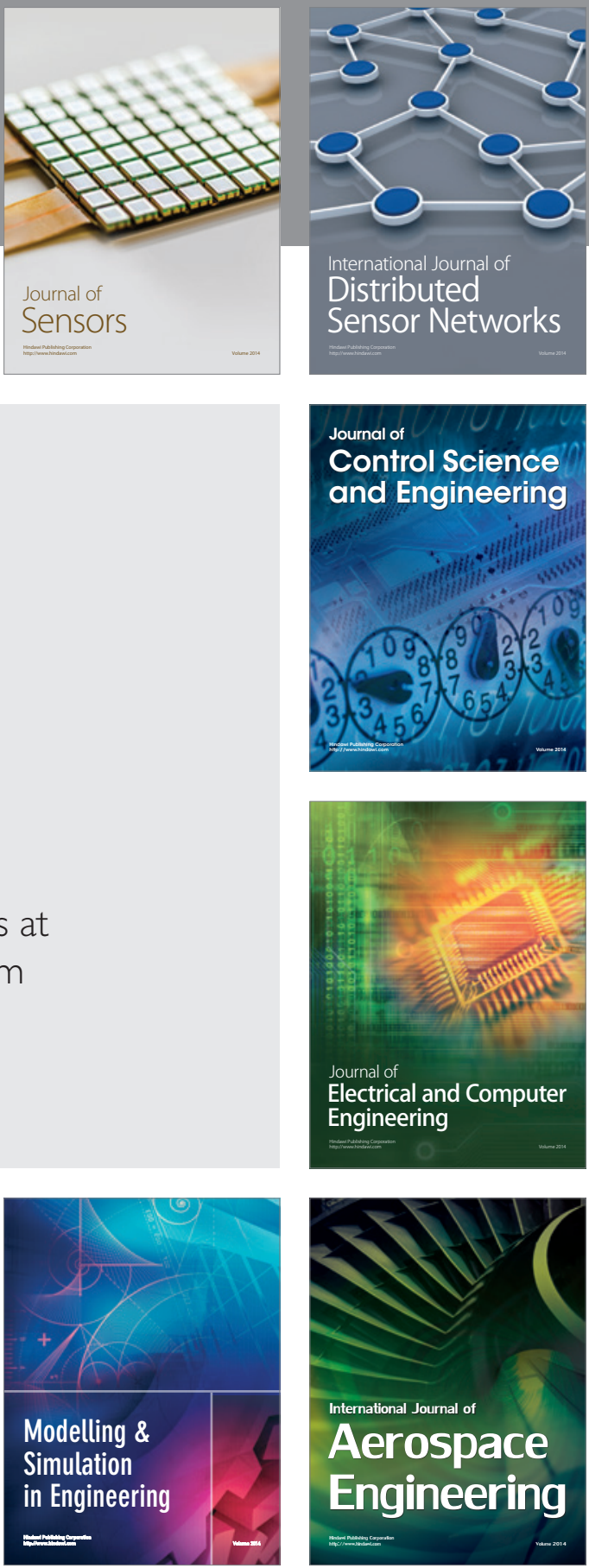

Journal of

Control Science

and Engineering
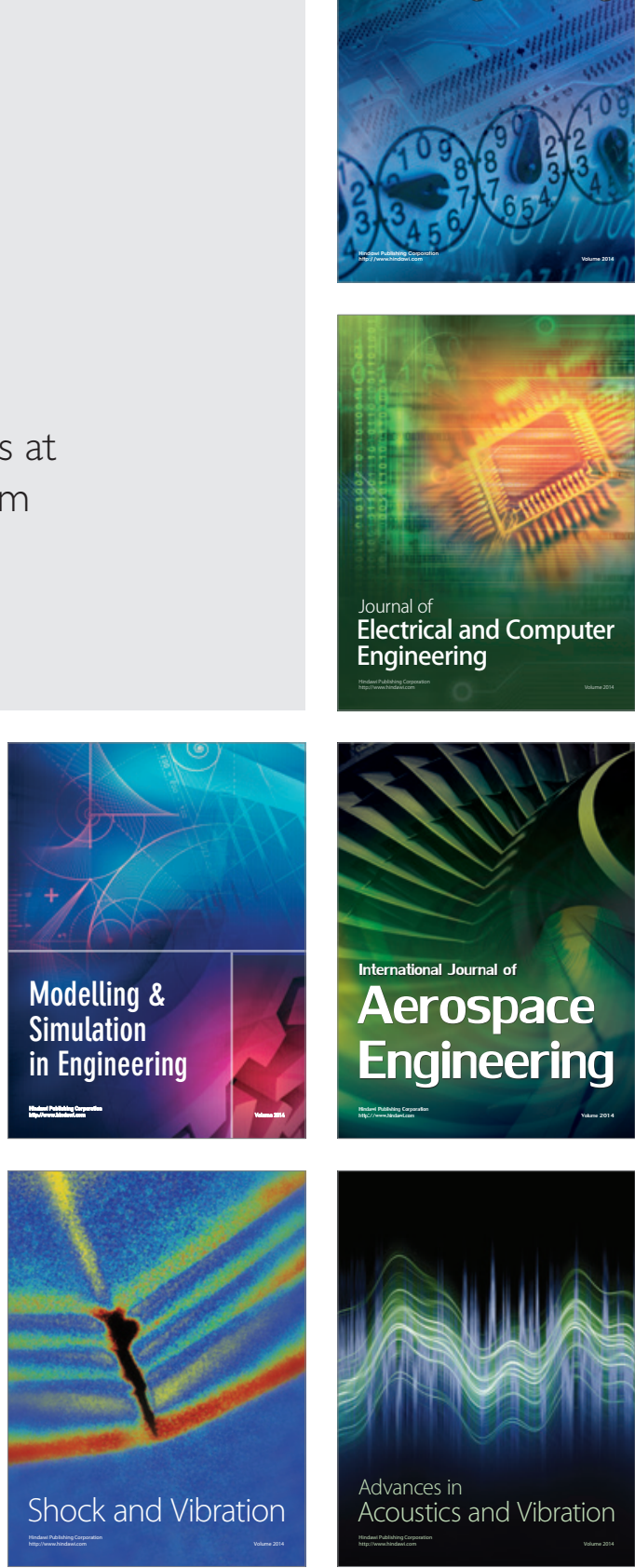